\title{
Succession of the Fungal Endophytic Microbiome in Wheat is Dependent on Tissue-Specific Interactions of Host Genotype and Environment
}

Meike Anna Christine Latz ( $\square$ latz@plen.ku.dk)

KTH Royal Institute of Technology Gene technology https://orcid.org/0000-0002-6583-9291

Mads Herbert Kerrn

Kobenhavns Universitet

Helle Sørensen

Kobenhavns Universitet

David Brian Collinge

Kobenhavns Universitet - Frederiksberg Campus

Birgit Jensen

Kobenhavns Universitet - Frederiksberg Campus

James K M Brown

John Innes Centre

Anne Mette Madsen

Nationale Forskningscenter for Arbejdsmiljo

Hans Jørgen Lyngs Jørgensen

Kobenhavns Universitet - Frederiksberg Campus

\section{Research}

Keywords: climate, endophytes, environment, fungi, genotype, microbiome, pathogens, Triticum aestivum (wheat)

Posted Date: July 22nd, 2020

DOI: https://doi.org/10.21203/rs.3.rs-44928/v1

License: (c) (i) This work is licensed under a Creative Commons Attribution 4.0 International License. Read Full License 


\section{Abstract}

Background: Fungi living inside seeds, leaves and roots of plants affect many aspects of plant health. Understanding the role of plant genotype, presence of fungal inoculum in the environment, abiotic environmental factors, and interaction of those factors in shaping the plant-associated fungal microbiome is of great relevance for modern agriculture. This knowledge can have direct implications in plant disease management, plant breeding, and development of microorganism-based biocontrol agents. These are important tools also in the context of increasing sustainability and adaption of crop production to a changing climate. In order to disentangle the effects of host genotype, environmental factors, and fungi present in seed stock, air and soil on endophytic fungal communities over one generation, we conducted a large-scale pot experiment with closely related cultivars of wheat over one growth-season. We studied fungi present inside the plants (endophytic fungi), in soil and air with metabarcoding, and monitored abiotic factors during the experimental period.

Results: Abiotic environmental factors, wheat genotype, and wheat tissue type were all found to influence fungal communities significantly. While the effect of wheat genotype was limited, there was evidence for host genetic control of fungal communities in leaves and roots but not in seeds. The degree of relatedness between wheat cultivars and resistance levels to the leaf disease STB was not reflected in the microbiome. The effect of host genetic control on the fungal community did not differ between abiotic environments. For the phyllosphere, abiotic environmental factors largely explained differences in fungal community abundance, diversity, and presence of pathogens between the locations, whereas locationdependent differences affected the rhizosphere communities to an only small extent. We found indications that airborne fungi are the primary source of inoculum for above-ground fungal communities of wheat, since a large proportion of leaf-associated fungi were also present in the air but not in soil and seed stocks.

Conclusions: Our study demonstrates how the factors genotype, environment, and presence of fungi in the environment shape the endophytic fungal community in wheat over one growing season.

\section{Background}

Plant-associated fungi can have important functions in growth and health of their host plant, by playing roles in disease resistance, nutrient acquisition, and abiotic stress tolerance [1-3]. Recently, the implications of plant-microbe interactions in modern agriculture have received much attention, potentially contributing to plant breeding strategies [4, 5], development of microbe-based biocontrol [6-9], and general understanding of the effect of plant domestication on the microbiome [10-12]. Internally colonising endophytic fungi are thought to have evolved with their host [13, 14], and due to their lifestyle are potentially more subjected to host genetic control than externally colonising microorganisms [15-17]. Despite the clear evidence of the economic significance of fungi in the plant microbiome, both as pathogens [18] and promoters of plant health $[15,19,20]$, their roles in the microbial community is still poorly investigated compared to bacteria. Considering the position of wheat as a staple food and main 
source of nutrition for a large proportion of the world population [21, 22], studying the factors influencing the associated fungal community, that also comprises many devastating pathogens [18,23,24], is of particular relevance. In this study, the term endophytic encompasses all microorganisms internally colonising the plant, despite their pathogenic or mutualistic lifestyle on the host plant.

Plant genetic control of the internal microbial community is of considerable interest for crop plant breeding and towards exploring the possibility to design a 'healthy' microbiome [25]. In laboratory-based studies, individual host plant mutations were found to affect composition of synthetic bacterial communities in the phyllosphere [26-28] and in roots [29]. In an agricultural setting of networks of interacting biotic and abiotic factors, the magnitude of the effect of genetic traits might vary depending on environmental conditions and microbial communities in the environment. Thus, the role of genetic traits established under controlled conditions might be overestimated, and context-dependent traits overlooked [30, 31]. A genotype effect on the fungal and bacterial microbiome has been found for closely related species of cereals [32], different populations of one species [33], or accessions/cultivars of wheat $[34,35]$ and other cereals $[36,37]$. However, the lack of knowledge on the degree of genetic relatedness limits the conclusions that can be drawn from these results.

In interaction with the host genotype, the growth location has a major effect on shaping the plant microbiome [33, 38-40]. Previous studies investigated the effect of field location on the fungal wheat microbiome [32, 34], but since field sites can differ in both biotic and abiotic factors, conclusions on which factors account for the variation are difficult to make. Environmental conditions, different microbial communities in the environment and soil properties can vary substantially between field sites. Locationdependent differences between the environmental microbiome as source of microbial inoculum have an influence on the plant microbiome [35, 40]. While soil [41], air [42], and seeds [43] have been individually investigated as sources of microbial inoculum, this is the first comprehensive study exploring the complex interaction of all three inoculum sources, environmental factors and plant genotype has not been conducted before.

In this study, we addressed the following questions: First, how do environmental differences between locations shape the wheat microbiome? Second, to which extent does plant genotype (cultivar) contribute to fungal community variation, and is genetic relatedness and resistance level to STB reflected in the community? Third, are tissue-specific communities equally influenced by the investigated factors? Finally, what are the inoculum sources for endophytic communities of wheat, and is there evidence for vertical seed-transmission to below- or above ground tissues? We show that seeds, leaves and roots harbour distinct fungal communities that are differentially affected by the environment; that the effect of host genotype is specific to leaves and roots and not dependent on environment; that genetic relatedness is not reflected in the microbiome; and that the microbiome in the phyllosphere is shaped by airborne fungi and the rhizosphere by soil fungi. These observations can have practical implications in an agricultural context, since knowledge of the natural shaping factors of the microbiome can guide us in improving mode of application and thereby also potentially efficiency of microbial biocontrol agents. 


\section{Methods}

\section{Experimental design}

The seed material used in this project from the twelve British winter wheat cultivars Cinnabar, Durin, Hedgehog, Hobbit, Hornet, Longbow, Mandate, Maris Beacon, Mithras, Norman, Rapier and Sportsman that had been grown and harvested from the same field at the John Innes Centre, UK. The cultivars were selected based on relatedness, differences in resistance levels to STB based on quantitative resistance, and presence/absence of the STB resistance gene Stb15. The experiment was carried out at the field station 'Højbakkegaard' at the University of Copenhagen in Taastrup, DK. Ten pots per cultivar (eight + two reserve pots) were filled with $10 \mathrm{~L}$ well-mixed sandy loam soil from an organic field close to the experimental location, where wheat had been grown the previous year. Five wheat seeds were sown in each pot and covered with a $4 \mathrm{~cm}$ layer of 'Perlite' (sowing date: 27.4.2017). Four samples of $50 \mathrm{~g}$ soil were collected for microbiome analysis and stored at $-20^{\circ} \mathrm{C}$ until further processing. After a germination period of one week in the greenhouse, the wheat seedlings were vernalised for 8 weeks at $5{ }^{\circ} \mathrm{C}$. Subsequently, five pots of each cultivar were placed outside (Fig. 1a) into the field environment (29.06.2017). The remaining five pots were transferred to a greenhouse chamber, where temperature and humidity were adjusted according to the outside conditions and no other plants present. Plants were irrigated throughout the growth period with water supplemented with fertiliser (final solution: EC 2.0, using 'Pioner NPK Basis', Horticoop Scandinavia A/S, Tilst, Denmark). One treatment with the fungicide 'Prosaro' (active ingredient prothioconazole and tebuconazole, Bayer AG, Leverkusen, Germany) for powdery mildew control was applied to all plants (6.7.2017), 6 weeks before the first plant sampling time point, when individual colonies were observed on single plants. The wheat cultivars varied greatly in partial resistance to powdery mildew, therefore it was important to prevent an epidemic.

\section{Air sampling}

Starting at the time point when the plants were transferred to the field or controlled greenhouse environment, airborne microorganisms were sampled in both locations using GSP samplers (Gesamtstaubprobenahme, CIS by BGI, INC Waltham, MA, USA) connected to 'Apex' air sampling pumps (Casella CEL, Buffalo, NY, USA). This sampling method has previously been successfully used for sampling of airborne fungi and bacteria [44]. The two air samplers were mounted with polycarbonate filters (37 mm, pore size $1.0 \mu \mathrm{m}$, GVS Life Sciences, Zola Predosa, Italy) and airborne microorganisms sampled for approx. $14 \mathrm{~h}$ at a flow rate of $3.5 \mathrm{~L} \mathrm{~min}^{-1}$ on a fixed day every week, by placing the air samplers in close vicinity to the plants. The filters were collected directly after sampling and stored at $-80^{\circ} \mathrm{C}$ until further processing. Air sampling was carried out for 12 weeks, until the seeds were mature and harvested, and a total of 24 filters were collected from both sampling locations.

\section{Plant sampling and sample processing}

After 8 weeks in the greenhouse or field, leaves and roots were sampled at anthesis (BBCH 65) within two consecutive days. From four pots (biological replicates) one plant was sampled from each, collecting the 
whole roots and four flag leaves from individual tillers. Roots were washed in water until soil was removed, and further processed the same day together with leaf samples. When the plants were matured (BBCH 92), four ears were collected from one plant, growing in the same pot from which leaves and roots were sampled at anthesis, and seeds separated from the husk. Plants grown in the field environment took two weeks longer to mature and were taken into a greenhouse chamber to ripen before sampling, because of wet weather conditions.

\section{Surface sterilisation}

Leaf, root and seed samples were processed on the day of sampling under sterile conditions (laminar flow bench). The samples were surface sterilised by an initial rinse in $70 \%$ ethanol, incubation for $2 \mathrm{~min}$ in $\mathrm{NaOCl}$ followed by three washing steps with sterile MilliQ water. The concentration of $\mathrm{NaOCl}$ for the surface sterilisation was adjusted depending on the plant tissue, $0.5 \%$ was used for leaves, $3 \%$ for roots and $7 \%$ for seeds. Subsequently, samples were frozen at $-20^{\circ} \mathrm{C}$ until further processing. All further processing and handling steps were carried out under sterile conditions in a laminar flow bench.

\section{Sample processing}

The samples were transferred to $20 \mathrm{ml}$ vials (Polyvials V, HDPE, Zinsser Analytic, Frankfurt am Main, Germany) and lyophilised. The samples were ground using zirconium oxide grinding balls on a 'SO-40a' shaker (Fluid Management Inc., Wheeling, IL, USA) until pulverised. The balls were previously surface sterilised with $0.5 \mathrm{M} \mathrm{HCl}$ for 3 min under shaking. Two $10 \mathrm{~mm}$ balls were added to each seed sample and four $5 \mathrm{~mm}$ balls to each leaf and root sample. Between processing steps, the samples were stored at $-20^{\circ} \mathrm{C}$.

\section{Sequencing of fungal communities}

\section{DNA extraction}

All steps were carried out under sterile conditions in a laminar flow bench. DNA was stored at $-80^{\circ} \mathrm{C}$, and the number of thaw-freeze cycles minimised.

Soil: DNA was extracted from $400 \mathrm{mg}$ soil using the 'NucleoSpin Soil' kit (Macherey-Nagel, Düren, Germany), following the manufacturer's instructions and adding an additional lysis step of 5 min vortexing with glass beads. Clean-up of eluted DNA was performed with 'E.Z.N.A. MicroElute DNA Cleanup' kit (Omega bio-tek, Georgia, USA), following the manufacturer's protocol.

Plant samples: DNA was extracted from leaf, root and seed samples using the 'E.Z.N.A. SP Plant DNA' kit (Omega bio-tek, Georgia, USA), following the manufacturer's instructions, with an extension of the lysis step by vortexing for $10 \mathrm{~min}$ in SP1 buffer with $1 \mathrm{~g} 0.7 \mathrm{~mm}$ sterile 'Garnet Beads' (Omni International Inc, Georgia, USA). 
Air samples: Air sample filters were cut into several smaller pieces and subsequently, DNA was extracted as described above for plant samples.

\section{Generation and processing of ITS1 metabarcoding data}

The ITS1 (nuclear ribosomal internal transcribes spacer) region was used as target for metabarcoding in this study. It was suggested as a universal DNA barcode marker for fungi and has been widely used in fungal community studies [45]. To optimise unbiased coverage of the fungal endophyte community in the plant and to minimise amplification of plant ITS, different PCR primers for metabarcoding studies [46, 47] were compared. The selection was made based on highest number of mismatches to the wheat ITS region of ten wheat cultivars (downloaded from $\mathrm{NCBI}$ ) and highest similarity to ten abundant wheat associated ascomycete and basidiomycete species, using the Muscle alignment tool of CLC Workbench. The primer pair ITS1-F [48] and 58A2R [49] was selected, since it has also been successfully used in recent fungal wheat microbiome studies [32,34]. Primers with Illumina adapters (58A2R-NGS (51 bases) GTC TCG TGG GCT CGG AGA TGT GTA TAA GAG ACA GCT GCG TTC TTC ATC GAT \& ITS1F-NGS (55 bases) TCG TCG GCA GCG TCA GAT GTG TAT AAG AGA CAG CTT GGT CAT TTA GAG GAA GTA A) were used for amplification of the fungal ITS1 region. Three PCR reactions each with 20 ng DNA were carried out for each sample, using the 'DreamTaq PCR Master Mix' (Thermo Scientific, Massachusetts, USA) in a final volume of $25 \mu \mathrm{l}$. All PCR reactions were carried out in a 2720 thermal cycler (Applied Biosystems, Massachusetts, USA) with an initial DNA denaturation step of $94^{\circ} \mathrm{C}$ for 5 min, followed by 30 cycles at $94{ }^{\circ} \mathrm{C}$ for $30 \mathrm{~s}, 48^{\circ} \mathrm{C}$ for $30 \mathrm{~s}, 72{ }^{\circ} \mathrm{C}$ for $40 \mathrm{~s}$, and a final elongation step at $72{ }^{\circ} \mathrm{C}$ for $10 \mathrm{~min}$. Following, the PCR products were cleaned using the 'Wizard SV Gel and PCR Clean-Up' kit (Promega, Madison, USA), following the manufacturer's protocol, and the DNA concentration adjusted. Indexing and sequencing was performed on a total of 364 samples in one lane of Illumina HiSeq $2 \times 250$ by 'Macrogen', Seoul, Korea. Sequencing resulted in 55,212,889 reads, with $92.2 \pm 1.0 \%$ of the bases reaching a Phred quality score of $>$ Q30.

Processing of the sequencing data was performed in QIIME2 (2018.4) [50]. Sequence quality control, including denoising, trimming and chimera removal was achieved with DADA2 [51], which outputs amplicon sequence variants (ASVs). Sequences with $>90 \%$ identity to the wheat ITS region (NCBI FJ609737.1) were removed for downstream analyses. On average, $20.45 \%$ of the reads in plant samples resulted from amplification of plant DNA, with generally higher percentages in sample types with low abundance of fungal DNA. From 153,369 \pm 57,870 (mean \pm SD) observations per sample, 94,499 \pm 55,212 remained after quality filtering and removal of plant-derived sequences. The q2-feature classifier [52] was used for taxonomic classification of ASVs, using a dynamic classifier that assigned a taxonomy based on $97 \%$ or greater sequence identity to the UNITE database [53] (version released 1.12.2017). ASVs that were not assigned to kingdom level were removed from the dataset.

\section{Statistical analyses}

Data analyses and preparation of figures were performed in R version 3.5.2 [54], using the packages 'Ime4' [55], 'vegan' [56] and 'ggplot2' [57]. 
We made non-metric multidimensional scaling (NMDS) plots to visualise the grouping of the observations based on dissimilarities. NMDS was performed based on Jaccard dissimilarity using the 'vegdist' function from the 'vegan' package in R [56], as a measure of the dissimilarity of all observation based on their ASV composition. We also tested Bray-Curtis dissimilarity, but did not achieve convergence. The NMDS plots were made with three dimensions, on the data with omitted observations of less than 1000 ASV reads (10 observations). Furthermore, we only examined the ASVs which had a total count over all observations of more than $0.1 \%$ of the total ASV count.

Diversity was measured by the Shannon index using the 'vegan' package in R [56]. Shannon and NMDS scores were analysed with a linear mixed model with fixed effects location + cultivar + tissue, and interactions: (location $\times$ cultivar $\times$ tissue or location $\times$ cultivar + tissue $\times$ cultivar and tissue $\times$ location) and random effect of pot. All linear mixed models were fitted with the Ime4 package [55].

The 'adonis' function from the 'vegan' R package [56] was used to give an impression of how much of the variance in the data set was described by each covariate. We plotted the $R^{2}$ value which was calculated by normalising the sequential sum of squares. These were found by adding one covariate at a time then calculating the sequential sum of squares each time. The linear model with Shannon index as response and covariates cultivar, location, and tissue was fitted.

The abundance of the most abundant genera was displayed using two kinds of abundance plots: relative and absolute. The relative abundance plots show bars indicating the relative abundance of each genus in the specific observation. The absolute abundance plots show the absolute count of each of the most abundant ASV's averaged over the four observations for each cultivar and location.

Venn diagrams were made to compare the ASV composition within different environments. Each intersection of a number of areas represent the number of ASVs which are present in all the intersecting areas.

\section{Results}

We cultivated twelve closely related winter wheat cultivars [58] with different levels of resistance to Septoria tritici blotch (STB) [59] in two different locations over one generation (Fig. 1a,b,c), provided with the same environmental microbiome in soil, air and seed stock, but different abiotic environmental conditions (Fig. 1d-g). Replicated experimental blocks within the locations, sampling of different plant tissues (Fig. 1C), and monitoring of all sources of fungal inoculum allowed us to assess multiple scales of host plant and environmental factors that influenced composition and abundance of the fungal microbiome (Fig. 1h).

We collected 4 bulk soil samples, 24 air samples, and 312 plant samples. Within the plant samples, 24 samples were taken for endophytic fungal community analysis of the seed stocks. The remaining 288 plant samples represented 192 individual plants (two per pot, one for leaf/root and one for seeds) from 12 cultivars, and comprised 96 leaf, 96 root and 96 seed samples (Additional file 1: Fig. S1). We identified 
5099 amplicon sequence variants (ASVs) that were assigned to fungi at $>97 \%$ identity. The phyla represented in the samples were 89.3\% Ascomycota, 6.1\% Basidiomycota, 0.4\% Mortierellomycota, 0.03\% Glomeromycota, and to a minor extent other phyla. Rarefaction curves indicated that sequencing depth sufficiently covered the fungal diversity in the samples (Additional file 2: Fig. S2).

\section{Plant tissue, location and genotype influence fungal communities}

All three tested experimental factors 'cultivar', 'location', and 'tissue' significantly affected a-diversity of fungal communities measured by the Shannon index (Table 1). While the two-way interaction of tissue with cultivar or location were also significant, 'cultivar $\times$ location' interaction did not significantly influence community diversity. The type of sample displayed the largest effect on Shannon diversity of fungal communities (Fig. 2a). The soil microbiome was most diverse, and diversity in plant samples was highest in roots, lower in seeds, and leaves harboured the least diverse microbiome. We investigated the impact of the factors tissue, location and cultivar on the fungal community with non-metric multidimensional scaling (NMDS). Cultivar, tissue and location all had significant effects on the NMDS1 score, even though the cultivar effect was not obvious from the NMDS plot (Fig. 2c). The effect of tissue and location were clearly visible in the NMDS plot (Fig. 2c,d). Even though the effect of cultivar was significant $(P=0.008$, Table 1), the relatedness between cultivars, disease resistance to STB and presence of an STB disease resistance gene did not correlate with differences in the fungal microbiome (Additional file 3: Fig. S3). 
Table 1

Effect of experimental factors on a-diversity of fungal communities associated with wheat.

\begin{tabular}{|c|c|}
\hline factor & Shannon \\
\hline \multirow[t]{2}{*}{ cultivar } & $\mathrm{Chi}^{2}{ }_{11}=30.393$ \\
\hline & $P=0.008$ \\
\hline \multirow[t]{2}{*}{ location } & $\mathrm{Chi}^{2}{ }_{1}=58.534$ \\
\hline & $P<0.0001$ \\
\hline \multirow[t]{2}{*}{ tissue } & $\mathrm{Chi}_{2}^{2}=286.138$ \\
\hline & $P<0.0001$ \\
\hline \multirow[t]{2}{*}{ cultivar $\times$ location } & $\mathrm{Chi}^{2}{ }_{11}=8.395$ \\
\hline & $P=1$ \\
\hline \multirow[t]{2}{*}{ cultivar $\times$ tissue } & $\mathrm{Chi}^{2}{ }_{22}=66.272$ \\
\hline & $P<0.0001$ \\
\hline \multirow[t]{2}{*}{ location $\times$ tissue } & $\mathrm{Chi}_{2}{ }_{2}=29.422$ \\
\hline & $P<0.0001$ \\
\hline \multicolumn{2}{|c|}{$\begin{array}{l}\text { Statistics describe linear mixed models of Shannon diversity (Shannon } \sim \text { cultivar }+ \text { location }+ \text { tissue }+ \\
\left(1 \mid \text { pot), } \text { Chi }^{2} \text { Df }=\text { LRT (likelihood ratio test), } P=\operatorname{Pr}(\text { Chi)) with single term addition or deletions. } P \text {-values }\right. \\
\text { are Bonferroni corrected by multiplication with } 6 .\end{array}$} \\
\hline
\end{tabular}

\section{Seeds, leaves and roots of wheat harbour distinct fungal communities}

Using the adonis test, tissue was estimated to account for $30.76 \%$ of the total variation in the dataset (Fig. 3). Therefore, from the factors investigated in this study, tissue had the largest effect on endophytic fungal communities of wheat. The effect was reflected in both community richness (Fig. 4) and the significant differences in diversity in an linear mixed model $((P<0.0001$, Table 1$)$, of Shannon diversity (Fig. 2a). Root samples displayed the highest diversity, with the number of ASVs being three times higher than in seed and leaf (5). Meanwhile, seed samples from the outside location contained the largest number of ASVs, as a measure of richness (Fig. 4). The seed stock samples harboured similar diversity, but reduced richness compared to seed outside samples (Fig. 2a, Fig. 5), potentially due to the storage of the seed stocks for approx. five years before the start of this study. Generally, abundance and diversity of fungal communities was lowest in leaf samples. 
A large fraction of the ASVs observed in plant samples was unique to each tissue (5d), and only few genera constituted shares of $>1 \%$ in different tissues (Fig. 4). These included Fusarium, Alternaria, Neoascochyta and Acremonium spp..

\section{Environment has a stronger effect on above-ground than below-ground plant parts}

After tissue, environment (location) had the second strongest effect on fungal communities in wheat in NMDS and adonis. Mean Shannon diversity index was significantly higher at the experimental site outside in the linear mixed model $(P<0.0001$, Table 1$)$. In addition, the number of common ASVs between tissues was larger outside than inside in Venn diagrams separated by location (Additional file 5: Fig. S5), indicating that the conditions outside are more favourable for colonisation by generalist fungi that are not plant tissue specific.

Temperatures outside were generally lower than inside the greenhouse and showed considerably higher fluctuations (Fig. 1d). Whereas both temperature and humidity in the greenhouse were relatively stable and did not fluctuate to a major extent (Fig. 1d,e), plants outside experienced on average $5{ }^{\circ} \mathrm{C}$ lower temperatures and considerably larger fluctuation between days. Furthermore, the plants outside were subjected to varying precipitation and wind intensity (Fig. 1f,g) throughout the period of the experiment. Fungi in the air did not significantly differ between inside and outside (Fig. 2a, Fig. 4).

All plant tissues were affected by the environmental differences between locations, but the effect size differed between plant tissues. Whereas seed samples displayed a clear separation by location in the NMDS (Fig. 2d), leaf samples of the two locations clustered more closely and the even more so the root samples. The observations from NMDS were also reflected in the Shannon diversity of the interaction of tissue and location (Fig. 2a), indicating that the differences between locations mainly affected the phyllosphere microbiome, and to a smaller extent the root microbiome. The adonis test for the individual tissues (Fig. 3) confirmed that location was, with an effect size of $47.67 \%$, the major driver of the seed microbiome, while the effect on leaf and seed was $12.72 \%$ and $2.71 \%$, respectively. The largest share variation in roots was not explained by either of the investigated factors (73.33\% variation) suggests that other parameters, possibly including local distribution of microorganisms and organic/inorganic matter, were the main shaping factors.

In addition to community diversity, differences in abundance between locations of many genera was more evident in above- than below-ground plant parts (Fig. 4). In seeds, several of the major genera from the outside location were not (or only to a small extent) present in seeds from the inside location, including Alternaria, Epicoccum, Monographella and Mycosphaerella spp.; whereas in roots, dominating genera were largely present in both locations. Therefore, the climate differences between locations were to a larger extent reflected in above- than belowground plant parts, while belowground parts were primarily shaped by other factors not captured in this study. 


\section{Fungi in the immediate environment are the major driver of communities in different plant parts}

When comparing soil and air microbiome with plant tissue samples by NMDS (Fig. 2c), NMDS scores for soil samples were located in the root cluster, while seed and leaf communities clustered closest to the air and the seed stock cluster. This might indicate that airborne inoculum is the major shaping factor of the leaf and seed microbiome, while soilborne fungi provide the inoculum for the root microbiome. Fungal diversity was significantly higher in roots than in seeds and leaves, likely reflecting the extensive microbial diversity in the immediate environment of the soil (Fig. 2a). Only $5 \%$ of the ASVs in air were also present in soil, indicating that the two are largely independent sources of microorganisms (5).

Eighty percent of the ASVs in leaf, seed and root, did not overlap with the microbiome of the local environment (soil, air and the seed stock) (5a-c). While fungal spores can proliferate within the host plant tissue and reach the detection limit, individual spores in environmental samples might escape detection. After subtracting the unique observations for tissues, almost $80 \%$ of the remaining ASVs of root were shared with soil, but only $15-20 \%$ with the seed stock and air (5e). On the other hand, $60 \%$ of ASVs in leaves and seeds were shared with the air. A large share (50\%) of the phyllosphere ASVs overlapped with the seed stocks, and this overlap was location-dependent, indicating that the seed stock was not the origin of these ASVs. A fraction of $25 \%$ of ASVs in the seed stocks were also present in air or soil, representing fungi that are generally present in the environment and not specific to seeds.

\section{Host genotype influences leaf and root communities, but has a weaker effect on seed fungal communities}

Although the effect of cultivar on the fungal microbiome was not apparent in the visualisation of NMDS, cultivar had a significant effect on Shannon diversity $(P=0.008$, Table 1). According to the adonis test (Fig. 3), cultivar explained $5.92 \%$ of the variation in the total dataset, but differed for individual tissues. Whereas cultivar explained approx. $25 \%$ of the variation observed in leaves and roots, the effect size on seeds was only $12.67 \%$ and the major variation of $48 \%$ was explained by location. Interestingly, the cultivar effect in the adonis test between locations (Fig. 3), was larger inside (12.67\%) than outside (5.55\%), even though the interaction was found not to be significantly associated with diversity (Table 1). Microbiome diversity did not correlate with relatedness between cultivars (data not shown), and neither the different levels of resistance to STB in the cultivars (Additional file: Fig. S3), nor presence of the major qualitative resistance gene Stb15 had a significant effect (data not shown).

\section{Abundance of pathogenic fungi differs between environments}

Fungi with a pathogenic lifestyle on wheat dominated the fungal microbiome in all plant tissues and both locations; even though only few disease symptoms visibly developed on the plants during the 
experimental period. We observed symptoms of powdery mildew (Blumeria graminis) and individual pustules of leaf rust (Puccinia triticina) on the foliage, and symptoms of Fusarium infection (Fusarium spp.) on the heads of the plants grown outside. Powdery mildew symptoms were treated with a single application of fungicide six weeks before sampling, since a heavy infestation would likely modify the fungal communities. Nevertheless, Blumeria was the predominant genus in the leaf microbiome (Fig. 4). In addition to powdery mildew, we observed individual spots of leaf rust on leaves outside, which was consistent with the elevated abundance of Puccinia spp. in those samples (Fig. 4), and chlorotic areas on the lower leaves of the outside plants. Even though the genus Zymoseptoria was highly represented in outside leaves, we did not observe the typical symptoms of STB (Zymoseptoria tritici). However, differences in Zymoseptoria abundance in leaves between locations were reflected in the air (Wilcoxon rank sum test, $P=0.040$ ), even though airborne fungal communities between locations did not differ significantly. Similar to leaves, seed microbiomes were dominated by a few pathogens or opportunistic pathogens. We observed pinkish fungal growth on the wheat heads from outside (but not inside) as signs of Fusarium infection and Fusarium head blight disease, and indeed Fusarium was the most abundant genus in those samples. The genera Fusarium, Monographella, Alternaria and Cladosporium were significantly overrepresented outside compared to inside, indicating that the conditions outside were more favourable for these fungi. Meanwhile, endophytic Penicillium and Acremonium spp. were significantly more abundant in seeds inside.

The fungal community of roots was generally more diverse. However, apart from pathogens, genera with reported mutualistic interaction potential were among the most abundant. The main pathogenic genera Fusarium (Fusarium root rot), Gaeumannomyces (take-all), and Microdochium were also responsive to location. The mutualistic endophytic Clonostachys spp. were primarily present in samples from outside, and endophytic Acremonium spp. in samples from inside which was also observed in seed samples. In general, fungal genera in roots were affected by location to a lesser extent than seed- and leafassociated ones.

\section{Discussion}

In this study, we demonstrated that several interacting factors contribute to shaping the fungal microbiome of wheat under partially controlled conditions. To our knowledge, this is the first study that considered the effect of airborne microorganisms and abiotic factors under field conditions, and the relatedness and presence of disease resistance genes of the cultivars on the microbiome. The British winter wheat cultivars used in this study were originally released in the 1960s to the 1990s, and previously investigated for genetic traits associated with susceptibility and resistance to STB [58, 59]. From this study, we selected cultivars in pairs of parent and offspring that possessed different levels of STB resistance (Fig. 1b). Genetically, the resistance of the selected cultivars was mainly based on quantitative resistance genes, which provide low-to-moderate resistance.

The host genotype contributed significantly to shaping the leaf and root fungal communities, an effect that was previously observed in studies of wheat leaves [32,34], wheat heads [40], and to some extent in 
the wheat rhizosphere [35]. In leaves, the effect of cultivar has been found to increase with leave age, whereas the effect of the environment decreased [34]. Another study found no clear cultivar effect by investigating endophytic communities by isolation [60], however the method was likely the limiting factor. On the other hand, differences in microbial communities were observed according to host maturity and host organs in this isolation approach [60], reflecting previous metabarcoding-based findings [34, 61] and the different fungal communities we observed between leaves, roots and seeds in this study.

Even though the genotype significantly influenced the endophytic fungal diversity in wheat, the genetic source of the variation is unclear. Fungal diversity did not correlate with relatedness between genotypes (data not shown), which would be an indicator of certain genetic traits that affect the microbial community. Furthermore, neither the different levels of phenotypic resistance to STB in the cultivars (Additional file: Fig. S3), nor presence of the major qualitative resistance gene Stb15 had a significant effect (data not shown). Potentially, differences in physiological traits between the cultivars are important determinants of the endophytic microbial communities. Even though the cultivars in this study were closely related, they displayed large variation in height, leave size, ear shape, amount of epicuticular wax, and most certainly other physiological characteristics that are not visible to the naked eye. Physiological leave attributes have previously been shown to differentiate microbial communities between spruce species; including water content, transpiration rate, stomatal conductance, and nitrogen/phosphorous/potassium content [62]. Furthermore, a number of individual host mutations in Arabidopsis that introduced alterations in surface structure, cell wall and defence signalling and patterntriggered immunity, and integral part of the plant's immune system, were shown to affect composition and/or abundance of the bacterial community $[26,28]$. Interestingly, the mutation affecting patterntriggered immunity affected only the endophytic community, but not the epiphytic community in leaves of Arabidopsis [28], also emphasising their differences in interactions with the host plant. This indicates, that mapping out physiological differences between cultivars might highlight characteristics for genotype-dependent differences in microbial communities. For this purpose, a more extensive set of welldescribed wheat cultivars is required.

As third factor investigated in this study, we found a significant effect of the location difference between field and greenhouse on the fungal communities in wheat. This effect, however, was likely not related to different fungal communities in the environment, since fungal communities present in the soil and air did not differ significantly between inside and outside (Fig. 4). It was previously found that the fungi present in air indoors are primarily determined by dispersal from the air outdoors [63], supporting our observation. The location-dependant differences we observed in plant microbiome composition and abundance therefore likely resulted from differences in the abiotic environment. Location-dependent effects on the wheat microbiome have previously been observed [32, 34, 64], however in these studies the location effect was a combination of biotic and abiotic factors. Higher temperatures, less temperature fluctuation and absence of mechanical stress through wind and rain provided optimal growth conditions for wheat grown in the greenhouse. In the endophytic community these factors were reflected by lower abundance and diversity of fungi, potentially due to heightened ability for defence. 
A fraction of $60 \%$ ASVs in leaves and seeds (excluding unique observations), were shared with the microbiome of the air samples (5e), supporting a hypothesis that the majority of the endophytic phyllosphere microbiome is airborne. Even though a large share (50\%) of the phyllosphere ASVs overlapped with the seed stocks, it is difficult to conclude that endophytic fungi were seed transmitted. Since the overlap of leaf microbiome with seed stock differed between locations, this indicates that those ASVs are probably derived from air or soil; and in fact, $25 \%$ of ASVs in seed stock are also present in air or soil. Therefore, the common ASVs between phyllosphere and seed stock likely reflect the specialisation of omnipresent fungi to wheat phyllosphere colonisation, rather than vertical transmission, as in systemic colonisation of the plant by seed-borne fungi.

All plant tissues were dominated by relatively few taxonomic groups representing many characterised pathogenic and saprotrophic fungi, and fewer species with described neutral or mutualistic endophytic lifestyle. The major fungal genera observed as endophytic colonists of wheat in this study have also been found as dominating in previous studies of the fungal communities on wheat, one of the most prevalent ones being Fusarium, Alternaria, Cladosporium, Microdochium, Zymoseptoria and Blumeria [40, 64]. Species belonging to the genera Clonostachys, Penicillium, and Acremonium have previously been reported as potential biocontrol agents of wheat diseases as Fusarium head blight and Septoria tritici blotch [65-67], therefore presence of these genera is of potential interest for future studies. Surprisingly, one cultivar displayed relatively high abundance of the foliar pathogen Blumeria in the roots, which was likely the result of a contamination during sample processing.

Other factors have been found to influence the wheat microbiome, but have not been addressed in this study. Cultivation methods or management strategies such as differ tillage practices $[35,68,69]$, infection with disease as Fusarium head blight [40] and treatment with fungicides have been investigated and found to significantly affect the fungal community.

\section{Conclusions}

Understanding the shaping factors of the plant-associated fungal communities is of great relevance for modern agriculture, both in the context of sustainability and increasing productivity. We argue that results from experiments with model plants, controlled environments, and synthetic microbial communities are transferable only to a limited extent to crop plants in an agricultural context, which went through a long process of domestication and inevitable coevolution of highly specialised pathogens. In order to gain a holistic understanding of plant genotype effects on the microbiome, we conducted this study in both field and controlled environments with a controlled environment microbiome, to disentangle the complex network of contributing environmental factors. Metatranscriptomics can further aid in understanding responses of host and associated microorganisms to one another and to changes in the environment, by revealing subtle changes in gene expression. Furthermore, genome-wide association studies (GWAS) have the potential to link host plant genetic variation to microbiome characteristics [27, 70]. GWAS on a group of genetically characterised and inbred wheat genotypes like the MAGIC population [71] can potentially unravel the genetic base of wheat genotype-associated differences in the microbiomes. 
Understanding the shaping of the endophytic plant microbiome under host genetic control will benefit the efforts of crop plant breeding $[4,72,73]$, but also development of microorganism-based biocontrol agents. Application of bacterial biocontrol agents on the flower of the parent, was shown to shape the microbiome of the progeny seed microbiomes [74]; therefore, knowledge about the natural source of inoculum for the microbiome of different tissues can also spur development of biocontrol agents.

\section{Declarations}

\section{Ethics and consent to participate}

Not applicable

\section{Consent for publication}

Not applicable

\section{Availability of data and material}

The dataset supporting the conclusions of this article is available as Additional files 6-8 [will be provided upon acceptance of the manuscript].

\section{Competing interests}

The authors declare that they have no competing interest.

\section{Funding}

This project has received funding from the European Union's Horizon 2020 research and innovation programme under the Marie Skłodowska-Curie grant agreement No. 674964.

\section{Authors' contributions}

MACL, HJLJ, DBC, BJ, and JB designed the experiment, JB and MACL selected the cultivars for the study, JB provided the seed material, AMM selected the method and provided the equipment for air sampling, MACL and HJLJ carried out the experiment, sampled and performed surface sterilisation of the plant tissues, MACL processed the samples, extracted DNA, carried out PCRs and bioinformatics processing of the sequencing data, MHK, HS and MACL performed statistical analyses, MHK and MACL visualised the data, MACL assembled the figures, interpreted the results and wrote the manuscript. All authors contributed to the final manuscript. 


\section{Acknowledgements}

We would like to thank the team leader of the plant growth facilities René Hvidberg Petersen for technical help with setup and carrying out of the experiment, Dominik Grosskinsky for his help with collecting the air filter samples during the experiment, and Chatchai Kosawang for inspiring discussions and providing the materials for DNA extraction.

\section{References}

1. Wani ZA, Ashraf N, Mohiuddin T, Riyaz-Ul-Hassan S. Plant-endophyte symbiosis, an ecological perspective. Appl Microbiol Biotechnol. 2015;99:2955-65.

2. Hardoim PR, van Overbeek LS, Berg G, Pirttilä AM, Compant S, Campisano A, et al. The hidden world within plants: Ecological and evolutionary considerations for defining functioning of microbial endophytes. Microbiol Mol Biol Rev. 2015;79:293-320.

3. Schlaeppi K, Bulgarelli D. The plant microbiome at work. Mol Plant-Microbe Interact. 2015;28:212-7.

4. Bakker MG, Manter DK, Sheflin AM, Weir TL, Vivanco JM. Harnessing the rhizosphere microbiome through plant breeding and agricultural management. Plant Soil. 2012;360:1-13.

5. Pieterse CMJ, de Jonge R, Berendsen RL. The soilborne supremacy. Trends Plant Sci. 2016;21:1713.

6. Pieterse C, Zamioudis C, Berendsen R, Weller D, Van Wees S, Bakker P. Induced systemic resistance by beneficial microbes. Annu Rev Phytopathol. 2014;52:347-75.

7. Backman PA, Sikora RA. Endophytes: An emerging tool for biological control. Biol Control. 2008;46:1-3.

8. Orozco-Mosqueda M del C, Rocha-Granados M del C, Glick BR, Santoyo G. Microbiome engineering to improve biocontrol and plant growth-promoting mechanisms. Microbiol Res. 2018;208:25-31.

9. Syed Ab Rahman SF, Singh E, Pieterse CMJ, Schenk PM. Emerging microbial biocontrol strategies for plant pathogens. Plant Sci. 2018;267:102-11.

10. Berendsen RL, Pieterse CMJ, Bakker PAHM. The rhizosphere microbiome and plant health. Trends Plant Sci. 2012;17:478-86.

11. Pérez-Jaramillo JE, Mendes R, Raaijmakers JM. Impact of plant domestication on rhizosphere microbiome assembly and functions. Plant Mol Biol. 2016;90:635-44.

12. Pérez-Jaramillo JE, Carrión VJ, de Hollander M, Raaijmakers JM. The wild side of plant microbiomes. Microbiome. 2018;6:143.

13. Redecker D, Kodner R, Graham LE. Glomalean Fungi from the Ordovician. Science (80-). 2000;289:1920-1.

14. Bidartondo MI, Read DJ, Trappe JM, Merckx V, Ligrone R, Duckett JG. The dawn of symbiosis between plants and fungi. Biol Lett. 2011;7:574-7. 
15. Saikkonen K, Wäli P, Helander M, Faeth SH. Evolution of endophyte-plant symbioses. Trends Plant Sci. 2004;9:275-80.

16. Ahlholm JU, Helander M, Henriksson J, Metzler M, Saikkonen K. Environmental conditions and host genotype direct genetic diversity of Venturia ditricha, a fungal endophyte of birch trees. Evolution. 2002;56:1566-73.

17. Saikkonen K, Wäli PR, Helander M. Genetic compatibility determines endophyte-grass combinations. PLoS One. 2010;5:e11395.

18. Savary S, Willocquet L, Pethybridge SJSJ, Esker P, McRoberts N, Nelson A, et al. The global burden of pathogens and pests on major food crops. Nat Ecol Evol. 2019;3:430-9.

19. Van Wees SC, Van der Ent S, Pieterse CM. Plant immune responses triggered by beneficial microbes. Curr Opin Plant Biol. 2008;11:443-8.

20. Zamioudis C, Pieterse CMJ. Modulation of host immunity by beneficial microbes. Mol Plant-Microbe Interact. 2011;25:139-50.

21. Curtis T, Halford NG. Food security: the challenge of increasing wheat yield and the importance of not compromising food safety. Ann Appl Biol. 2014;164:354-72.

22. Lobell DB, Cassman KG, Field CB. Crop yield gaps: their importance, magnitudes, and causes. Annu Rev Environ Resour. 2009;34:179-204.

23. Krattinger SG, Lagudah ES, Spielmeyer W, Singh RP, Huerta-espino J, Mcfadden H, et al. Pathogens in wheat. 2009.

24. Oerke E-C, Dehne H-W. Safeguarding production-losses in major crops and the role of crop protection. Crop Prot. 2004;23:275-85.

25. Morella NM, Weng FC-H, Joubert PM, Metcalf CJE, Lindow S, Koskella B. Successive passaging of a plant-associated microbiome reveals robust habitat and host genotype-dependent selection. Proc Natl Acad Sci. 2020;117:1148-59.

26. Bodenhausen N, Bortfeld-Miller M, Ackermann M, Vorholt JA. A Synthetic Community Approach Reveals Plant Genotypes Affecting the Phyllosphere Microbiota. PLoS Genet. 2014;10:e1004283.

27. Horton MW, Bodenhausen N, Beilsmith K, Meng D, Muegge BD, Subramanian S, et al. Genome-wide association study of Arabidopsis thaliana leaf microbial community. Nat Commun. 2014;5:5320.

28. Chen T, Nomura K, Wang X, Sohrabi R, Xu J, Yao L, et al. A plant genetic network for preventing dysbiosis in the phyllosphere. Nature. 2020;580:653-7.

29. Lundberg DS, Lebeis SL, Paredes SH, Yourstone S, Gehring J, Malfatti S, et al. Defining the core Arabidopsis thaliana root microbiome. Nature. 2012;488:86-90.

30. Yan J, Zhu J, He C, Benmoussa M, Wu P. Molecular marker-assisted dissection of genotype $\times$ environment interaction for plant type traits in rice (Oryza sativa L.). Crop Sci. 1999;39:538.

31. Cooper M, van Eeuwijk FA, Hammer GL, Podlich DW, Messina C. Modeling QTL for complex traits: detection and context for plant breeding. Curr Opin Plant Biol. 2009;12:231-40. 
32. Sapkota R, Knorr K, Jørgensen LN, O’Hanlon KA, Nicolaisen M. Host genotype is an important determinant of the cereal phyllosphere mycobiome. New Phytol. 2015;207:1134-44.

33. Wagner MR, Lundberg DS, del Rio TG, Tringe SG, Dangl JL, Mitchell-Olds T. Host genotype and age shape the leaf and root microbiomes of a wild perennial plant. Nat Commun. 2016;7:12151.

34. Sapkota R, Jørgensen LN, Nicolaisen M. Spatiotemporal variation and networks in the mycobiome of the wheat canopy. Front Plant Sci. 2017;8 August:1-10.

35. Simonin M, Dasilva C, Terzi V, Ngonkeu ELM, Diouf D, Kane A, et al. Influence of plant genotype and soil on the wheat rhizosphere microbiome: evidences for a core microbiome across eight African and European soils. FEMS Microbiol Ecol. 2020;96:fiaa067.

36. Edwards J, Johnson C, Santos-Medellín C, Lurie E, Podishetty NK, Bhatnagar S, et al. Structure, variation, and assembly of the root-associated microbiomes of rice. Proc Natl Acad Sci. 2015;112:E911-20.

37. Walters WA, Jin Z, Youngblut N, Wallace JG, Sutter J, Zhang W, et al. Large-scale replicated field study of maize rhizosphere identifies heritable microbes. Proc Natl Acad Sci. 2018;115:7368-73.

38. Fitzpatrick CR, Copeland J, Wang PW, Guttman DS, Kotanen PM, Johnson MTJ. Assembly and ecological function of the root microbiome across angiosperm plant species. Proc Natl Acad Sci. 2018;115:E1157-65.

39. Cornwell WK, Ackerly DD. Community assembly and shifts in plant trait distributions across an environmental gradient in coastal California. Ecol Monogr. 2009;79:109-26.

40. Rojas EC, Sapkota R, Jensen B, Jørgensen HJL, Henriksson T, Jørgensen LN, et al. Fusarium Head Blight Modifies Fungal Endophytic Communities During Infection of Wheat Spikes. Microb Ecol. 2020;79:397-408.

41. Zarraonaindia I, Owens SM, Weisenhorn P, West K, Hampton-Marcell J, Lax S, et al. The soil microbiome influences grapevine-associated microbiota. MBio. 2015;6:1-6.

42. Maignien L, DeForce EA, Chafee ME, Eren AM, Simmons SL. Ecological Succession and Stochastic Variation in the Assembly of Arabidopsis thaliana Phyllosphere Communities. MBio. 2014;5.

43. Hodgson S, de Cates C, Hodgson J, Morley NJ, Sutton BC, Gange AC. Vertical transmission of fungal endophytes is widespread in forbs. Ecol Evol. 2014;4:1199-208.

44. Frankel M, Timm M, Hansen EW, Madsen AM. Comparison of sampling methods for the assessment of indoor microbial exposure. Indoor Air. 2012;22:405-14.

45. Schoch CL, Seifert K a., Huhndorf S, Robert V, Spouge JL, Levesque C a., et al. Nuclear ribosomal internal transcribed spacer (ITS) region as a universal DNA barcode marker for fungi. Proc Natl Acad Sci. 2012;109:6241-6.

46. Toju H, Tanabe AS, Yamamoto S, Sato H. High-coverage ITS primers for the DNA-based identification of ascomycetes and basidiomycetes in environmental samples. PLoS One. 2012;7:e40863.

47. Bokulich NA, Mills DA. Improved selection of internal transcribed spacer-specific primers enables quantitative, ultra-high-throughput profiling of fungal communities. Appl Environ Microbiol. 
2013;79:2519-26.

48. Gardes M, Bruns TD. ITS primers with enhanced specificity for basidiomycetes - application to the identification of mycorrhizae and rusts. Mol Ecol. 1993;2:113-8.

49. Martin KJ, Rygiewicz PT. Fungal-specific PCR primers developed for analysis of the ITS region of environmental DNA extracts. BMC Microbiol. 2005;5:28.

50. Bolyen E, Rideout JR, Dillon MR, Bokulich NA, Abnet CC, Al-Ghalith GA, et al. Reproducible, interactive, scalable and extensible microbiome data science using QIIME 2. Nat Biotechnol. 2019;37:852-7.

51. Callahan BJ, McMurdie PJ, Rosen MJ, Han AW, Johnson AJA, Holmes SP. DADA2: High-resolution sample inference from Illumina amplicon data. Nat Methods. 2016;13:581-3.

52. Bokulich NA, Kaehler BD, Rideout JR, Dillon M, Bolyen E, Knight R, et al. Optimizing taxonomic classification of marker-gene amplicon sequences with QIIME 2's q2-feature-classifier plugin. Microbiome. 2018;6:90.

53. Nilsson RH, Larsson K-H, Taylor AFS, Bengtsson-Palme J, Jeppesen TS, Schigel D, et al. The UNITE database for molecular identification of fungi: handling dark taxa and parallel taxonomic classifications. Nucleic Acids Res. 2019;47:D259-64.

54. Team RC. R: A language and environment for statistical computing. Vienna, Austria. 2018.

55. Bates D, Mächler M, Bolker B, Walker S. Fitting Linear Mixed-Effects Models Using Ime4. J Stat Softw. 2015;67:1-48.

56. Oksanen J, Kindt R, Pierre L, O'Hara B, Simpson GL, Solymos P, et al. vegan: Community Ecology Package, $R$ package version 2.4-0. $R$ package version 2.2-1. 2016. https://cran.rproject.org/package=vegan. Accessed 25 Mar 2019.

57. Valero-Mora PM. ggplot2: Elegant Graphics for Data Analysis. J Stat Softw. 2010;35 Book Review 1.

58. Arraiano LS, Brown JKM. Sources of resistance and susceptibility to Septoria tritici blotch of wheat. Mol Plant Pathol. 2016;8 20 17:276-92.

59. Arraiano LS, Brown JKM. Identification of isolate-specific and partial resistance to Septoria tritici blotch in 238 European wheat cultivars and breeding lines. Plant Pathol. 2006;55:726-38.

60. Comby M, Lacoste S, Baillieul F, Profizi C, Dupont J. Spatial and Temporal Variation of Cultivable Communities of Co-occurring Endophytes and Pathogens in Wheat. Front Microbiol. 2016;7 MAR.

61. Gdanetz K, Trail F. The Wheat Microbiome Under Four Management Strategies, and Potential for Endophytes in Disease Protection. Phytobiomes. 2017;1:158-68.

62. Li Y, Wu X, Chen T, Wang W, Liu G, Zhang W, et al. Plant Phenotypic Traits Eventually Shape Its Microbiota: A Common Garden Test. Front Microbiol. 2018;9.

63. Adams RI, Miletto M, Taylor JW, Bruns TD. Dispersal in microbes: fungi in indoor air are dominated by outdoor air and show dispersal limitation at short distances. ISME J. 2013;7:1262-73.

64. Nicolaisen M, Justesen AF, Knorr K, Wang J, Pinnschmidt HO. Fungal communities in wheat grain show significant co-existence patterns among species. Fungal Ecol. 2014;11:145-53. 
65. Rojas EC, Jensen B, Jørgensen HJL, Latz MAC, Esteban P, Ding Y, et al. Selection of fungal endophytes with biocontrol potential against Fusarium head blight in wheat. Biol Control. 2020;144:104222.

66. Latz MAC, Jensen B, Collinge DB, Lyngs Jørgensen HJ. Identification of two endophytic fungi that control Septoria tritici blotch in the field, using a structured screening approach. Biol Control. 2020;141:104128.

67. Hue AG, Voldeng HD, Savard ME, Fedak G, Tian X, Hsiang T. Biological control of fusarium head blight of wheat with Clonostachys rosea strain ACM941. Can J Plant Pathol. 2009;31:169-79.

68. Karlsson I, Friberg H, Kolseth AK, Steinberg C, Persson P. Organic farming increases richness of fungal taxa in the wheat phyllosphere. Mol Ecol. 2017;26:3424-36.

69. Granzow S, Kaiser K, Wemheuer B, Pfeiffer B, Daniel R, Vidal S, et al. The Effects of Cropping Regimes on Fungal and Bacterial Communities of Wheat and Faba Bean in a Greenhouse Pot Experiment Differ between Plant Species and Compartment. Front Microbiol. 2017;8 MAY:1-22.

70. Beilsmith K, Thoen MPM, Brachi B, Gloss AD, Khan MH, Bergelson J. Genome-wide association studies on the phyllosphere microbiome: Embracing complexity in host-microbe interactions. Plant J. 2019;97:164-81.

71. Huang BE, George AW, Forrest KL, Kilian A, Hayden MJ, Morell MK, et al. A multiparent advanced generation inter-cross population for genetic analysis in wheat. Plant Biotechnol J. 2012;10:826-39.

72. Berg G, Köberl M, Rybakova D, Müller H, Grosch R, Smalla K. Plant microbial diversity is suggested as the key to future biocontrol and health trends. FEMS Microbiol Ecol. 2017;93:1-9.

73. Gopal M, Gupta A. Microbiome selection could spur next-generation plant breeding strategies. Front Microbiol. 2016;7 December:1971.

74. Mitter B, Pfaffenbichler N, Flavell R, Compant S, Antonielli L, Petric A, et al. A new approach to modify plant microbiomes and traits by introducing beneficial bacteria at flowering into progeny seeds. Front Microbiol. 2017;8.

\section{Figures}



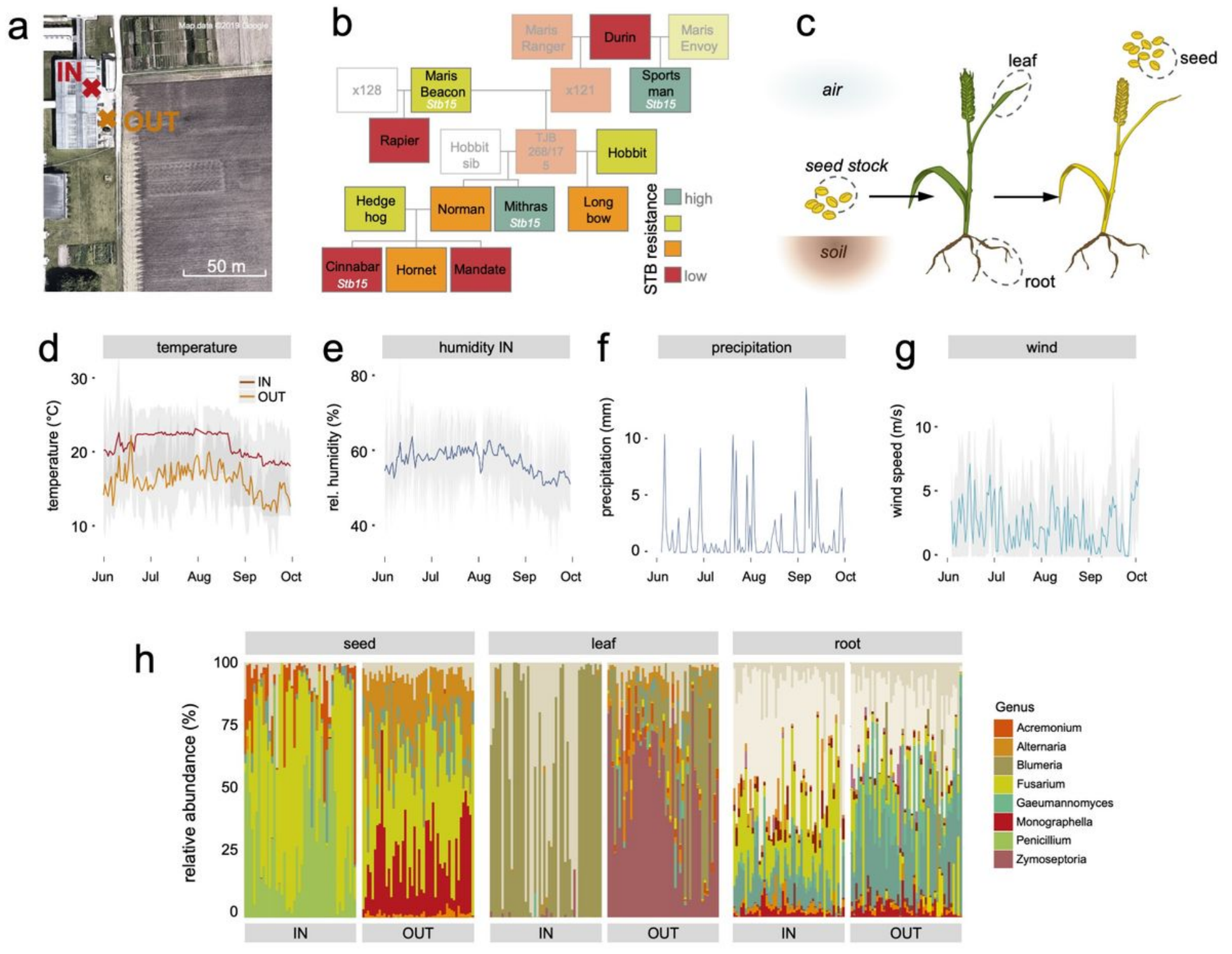

\section{Figure 1}

Summary of experimental design and analysis. (a) Satellite picture of the location of the experiment in Taastrup Højbakkegaard, Denmark (Map data (C2019 Google). A set of plants in pots were grown in a separate greenhouse chamber (IN) and, $25 \mathrm{~m}$ apart, outside surrounded by fields (OUT). (b) Family tree of the twelve winter wheat cultivars used in the experiment, with varying levels of resistance to STB; cultivars with light colours were not used in the experiment. Cultivars contain a known resistance gene to STB (Stb15) are marked. (c) Schematic representation of samples taken during the experiment from the wheat cultivars and the environment. Seed stock and soil were sampled at start of the experiment, air was sampled continuously throughout the experiment in both locations. (d-g) Locations differ in temperature and weather conditions. Observations of climate data for the experimental period, measurements taken every 5 minutes. (d) Daily mean of temperature $\left({ }^{\circ} \mathrm{C}\right)$ in location inside and outside with minimum and maximum observations (grey background). (e) Daily mean of relative humidity (\%) in location inside, with $\mathrm{min} / \mathrm{max}$ observations. (f) Precipitation in $\mathrm{mm}$ per day in location outside. (g) Daily mean of wind speed 
in metres per second, with min/max observations for each day. (h) Relative number of reads of the most abundant genera ( $>1 \%$ of total read number). Each sample is displayed individually.

a

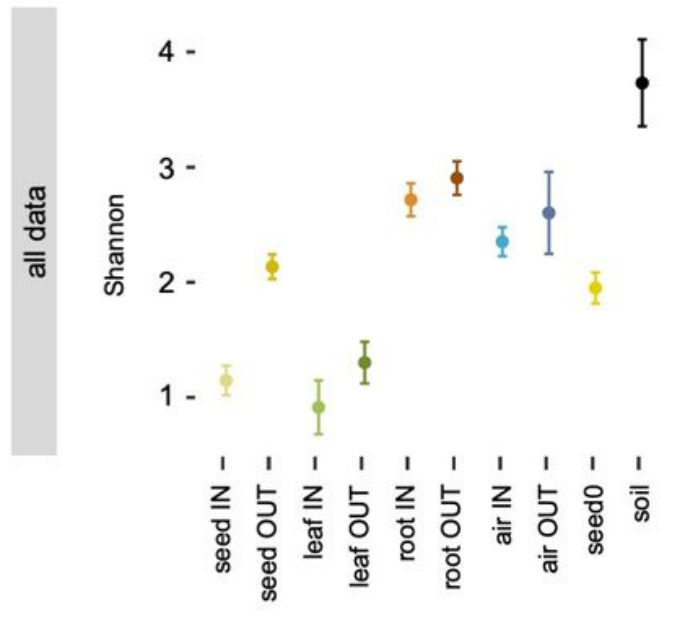

b location $\mathrm{x}$ tissue $\mathrm{x}$ cultivar

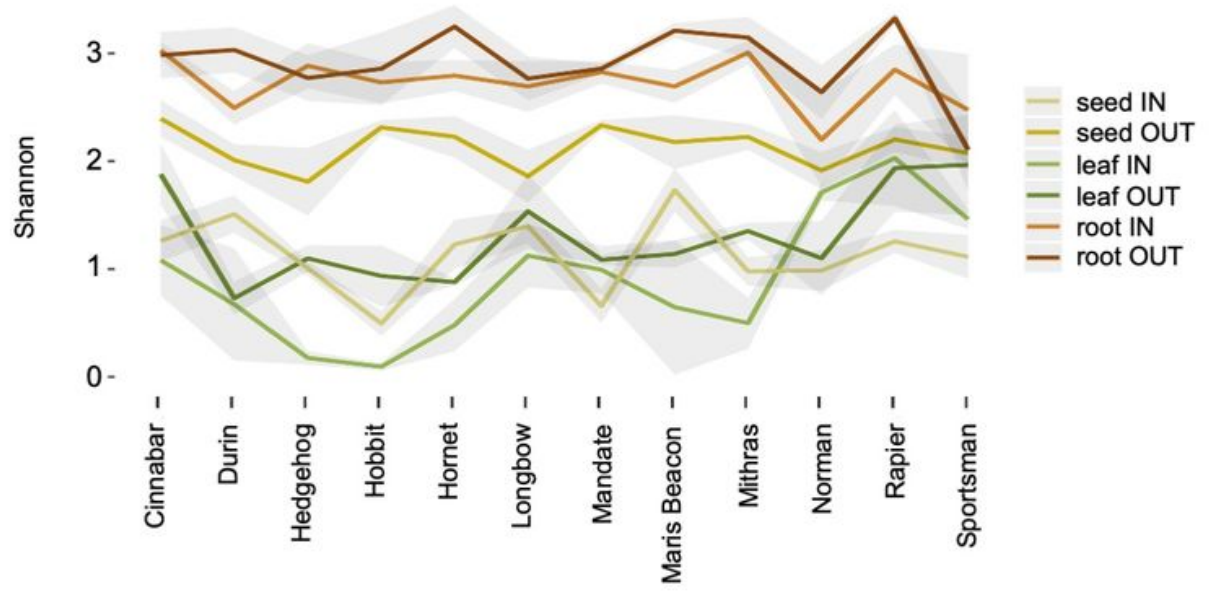

C

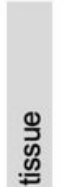

0.25 -

号

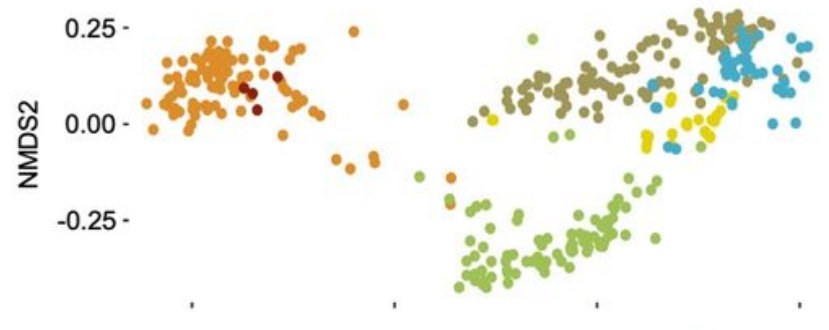

들

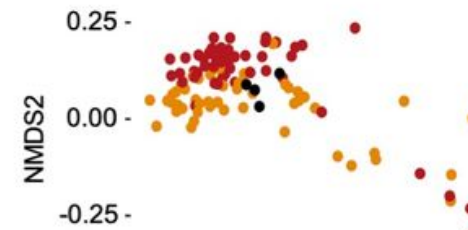
$-0.25-$

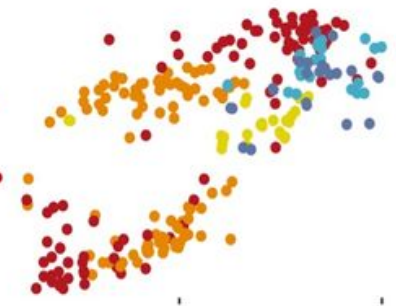

离

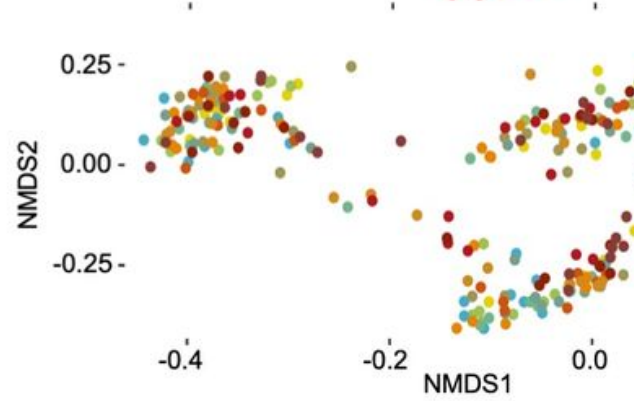

all data
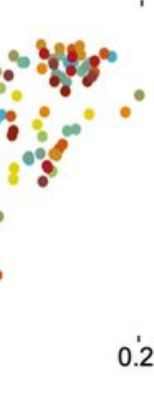

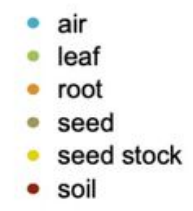

- IN

- OUT

- air IN

- air OUT

- seed stock

- soil

- Cinnabar

- Durin

- Hedgehog

- Hobbit

- Hornet

- Longbow

- Mandate

- Maris Beacon

- Mithras

- Norman

- Rapier

- Sportsman

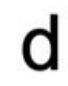

location
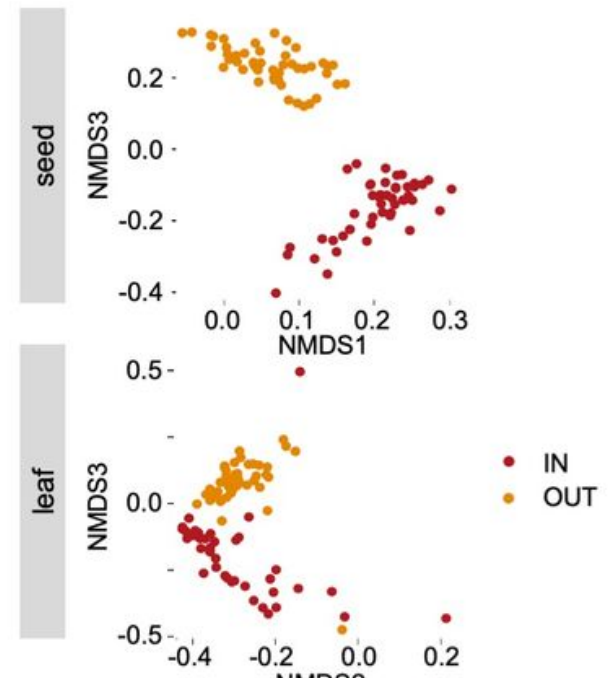

훙

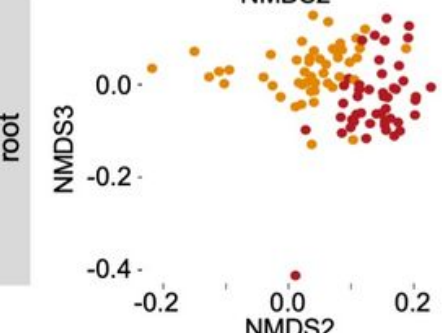

Figure 2

Tissue, environment and cultivar influence $\bigotimes$ - and $\beta$-diversity of endophytic fungal communities in wheat. Sample sizes are $n=96$ for leaf, roots and seed, respectively, $n=24$ for seed stock, $n=24$ for air, and $n=4$ for soil. (a) Mean Shannon diversity index was higher at experimental site outside (and differed for tissues in the additive linear model. Error bars represent the standard error of the mean. (b) Wheat cultivars (x axis) 
had a minor but significant effect on Shannon diversity. Each point represents the mean of four replicates, hence the standard error of the mean (shaded area) should not be considered too strictly. (c) The factors tissue, location and cultivar have a significant effect on the NMDS1 score (ANOVA, $F 22,206=2.52, P<0.00037$ ), even though the cultivar effect is not detectable in the NMDS. NMDS including all data, coloured by tissue (top), location (middle), and genotype/cultivar (bottom). Distance between observations is based on Jaccard dissimilarity, and included ASVs which reflected $>0.1 \%$ of the total number of observations. 10 observations with $<1000$ observations were omitted. (d) The effect size of experimental site was larger in above- than below-ground plant tissue. NMDS of seed (top), leaf (middle), and root (bottom) coloured by environmental site inside and outside.

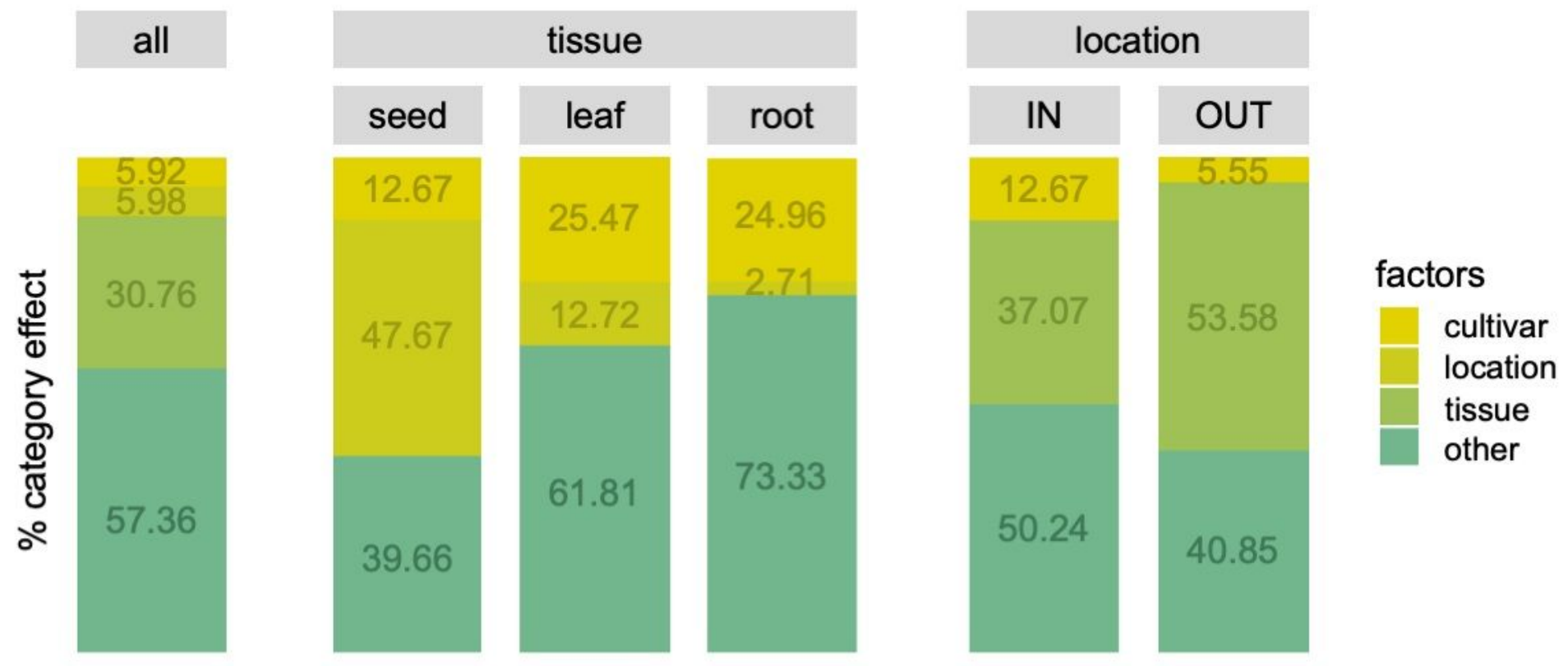

\section{Figure 3}

Effect size of plant genotype and location differ depending on tissue. Adonis test displaying the percent variation explained by the factors cultivar, location and tissue in all plant samples, and by tissue and by location. R2 values as a measure of effect size were calculated from additive models with Shannon as response and cultivar, tissue and location as covariates (all), with cultivar and location as covariates (tissue), and with location and tissue as covariates (location). Interaction effects between the factors and other undefined effects are summarised under 'other'. 


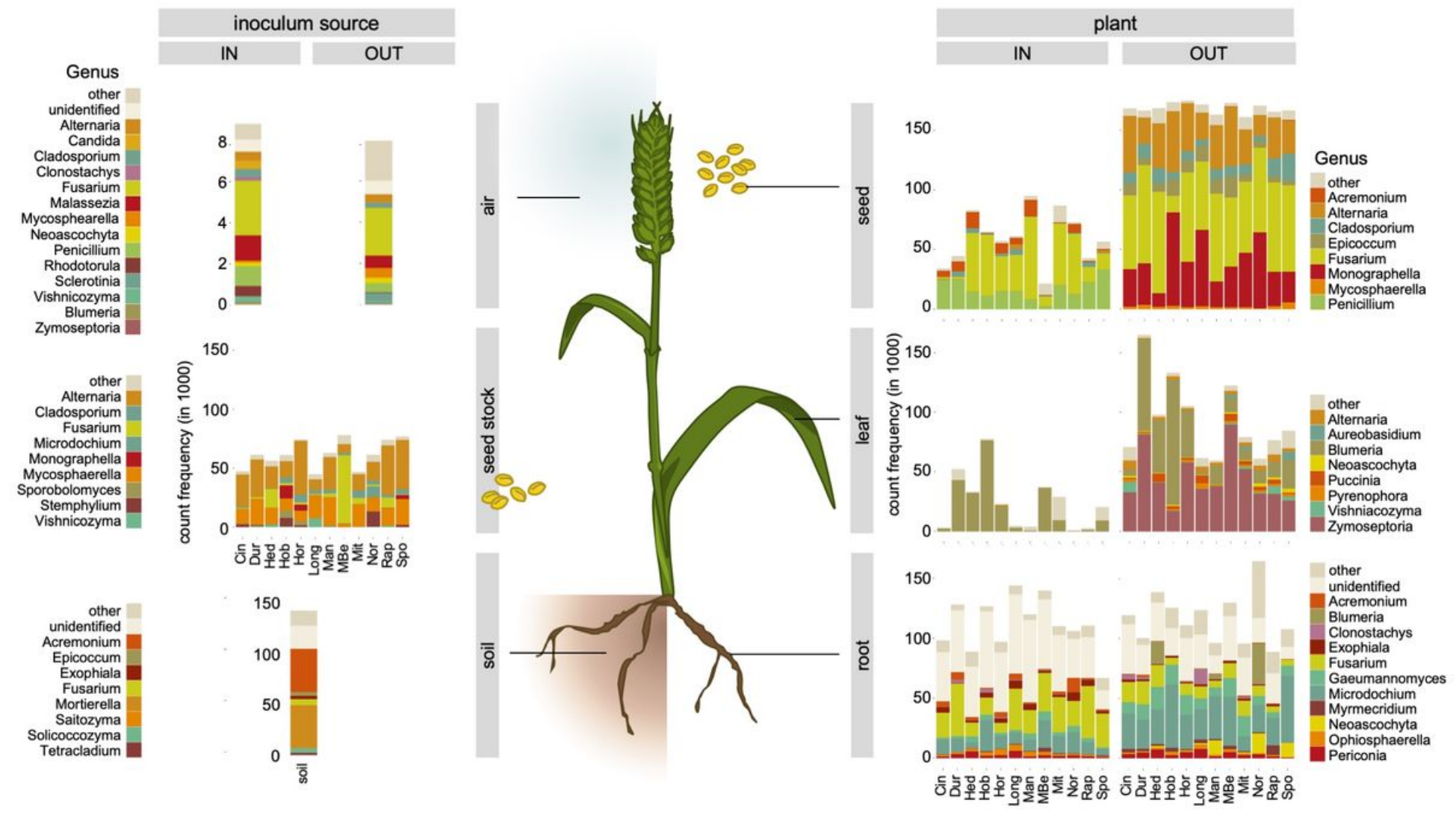

Figure 4

Major genera across cultivars have a pathogenic lifestyle, are tissue-specific and affected by location. Mean abundance of dominant ( $>1 \%$ of total reads) fungal genera in different tissues of twelve wheat cultivars (names abbreviated). Genera with lower abundance ( $<1 \%$ of total reads) are represented in "other". Air samples over the time period from one location are summarised.

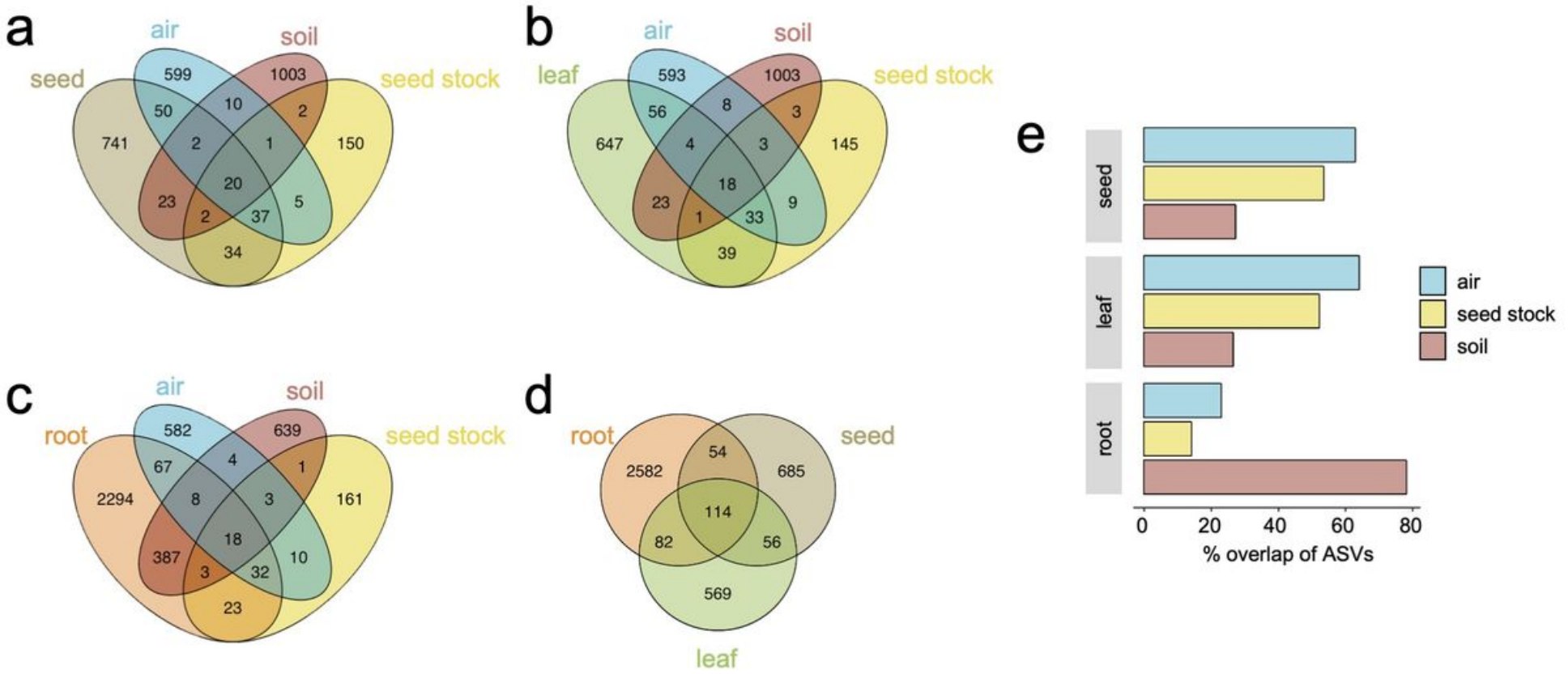

Figure 5 
Different wheat habitats harbour distinct microbial communities. Venn diagrams with intersections displaying common ASVs in the areas. (a-c) Common ASVs of plant tissues (a) seed, (b) leaf and (c) root with the surrounding environment (seed stock, air, and soil). (d) ASVs shared between the tissues. The diagrams sum the data between locations; diagrams separated by location are displayed in Additional file 5: Fig. S5. (e) Presence of fungi in the immediate environment is the major driver of communities in different plant parts. Bar chart of relative number of ASVs that overlap with the environmental communities in air, seed stock and soil. $80 \%$ of the ASVs in all tissues were not present in the environment, and not taken into consideration for the bar chart.

\section{Supplementary Files}

This is a list of supplementary files associated with this preprint. Click to download.

- Additionalfile5FigS5.tiff

- Additionalfile4FigS4.tiff

- Additionalfile3FigS3.tiff

- Additionalfile2FigS2.tiff

- Additionalfile1Figs1.tiff 